\title{
PESQUISA AÇÃO-PEDAGÓGICA: PRÁTICAS DE EMPODERAMENTO E PARTICIPAÇÃO
}

\author{
RESERCH PEDAGOGIC-ACTION: \\ EMPOWERMENT PRACTICES AND PARTICIPATION
}

\author{
INVESTIGACIÓN ACCIÓN-PEDAGÓGICA: \\ PRÁCTICAS DE EMPODERAMIENTO Y PARTICIPACIÓN
}

\section{Maria Amélia Santoro Franco ${ }^{1}$}

\begin{abstract}
RESUMO
Para reconfigurar uma ação pedagógica, na dimensão de prática colaborativa, é fundamental que pesquisadores e professores engajem-se em processos mútuos de aprender-ensinar; de estranhar-compreender. É preciso tempo e espaço para que professores/pesquisadores e sujeitos da prática sejam, ao mesmo tempo, participantes e protagonistas. Considerar esse mútuo protagonismo é viabilizar a construção do processo de conscientização na perspectiva freireana, qual seja a criação de circunstâncias que produzam rupturas e tensões na consciência ingênua, criando possibilidades de contrapontos construtivos na direção de consciência crítica. O trabalho pauta-se em pesquisas-ações realizadas nesta perspectiva e que subsidiam a proposta aqui delineada de construir os princípios de uma pesquisa-ação pedagógica que produza empoderamento nos docentes, a partir da questão problema: Como os professores, alijados historicamente do papel de participantes ativos e inseridos em sua maioria em processos de pauperização da profissão, podem encontrar forças e caminhos para constituírem-se como atores sociais, críticos e comprometidos com uma nova concepção de vida e mundo? A meta-análise realizada a partir de pesquisas-ações antecedentes (FRANCO) através da hermenêutica crítica (THOUARD) indica que a organização de dispositivos pedagógicos como estruturantes de um universo comum de conhecimentos, na perspectiva de Paulo Freire, pode funcionar como fundamento para processos de conscientização. Tais dispositivos parecem agilizar uma triangulação praxiológica que contribui para a articulação entre teorias, práticas e valores de todos os participantes.
\end{abstract}

PALAVRAS-CHAVE: Pesquisa-ação pedagógica. Formação de professores. Empoderamento. Consciência crítica.

\begin{abstract}
To reconfigure a pedagogical action, until the collaborative practice perspective, is essential that researchers and teachers engage in mutual learning processes teaching; process surprising-understanding. Itneeds time and space for teachers / researchers and subjects of the practice be at the same time, participants and protagonists. Consider this mutual role is to enable the construction of educational process in Freire's perspective, what is the creation of circumstances that produce ruptures and tensions in the naive consciousness, creating opportunities for constructive counterpoint toward critical consciousness. This paper is working on research-actions I realized in this perspective and that subsidize the outlined proposal to build the principles of pedagogical action research that produces empowerment on teachers from the problem question: As teachers, historically priced out of the social role of active participants and included mostly in impoverishment processes of the profession can find the strength and ways to constitute themselves as social actors, critics and committed to a new conception of life and world? A meta-analysis carried out from background researchactions (FRANCO) through critical hermeneutics (THOUARD) indicates that the organization of teaching devices as structuring a common universe of knowledge from the perspective of Paulo Freire can works as a foundation for awareness processes. Such devices appear to expedite a praxiological triangulation contributing to the link between theories, practices and values of all participants.
\end{abstract}

\footnotetext{
${ }^{1}$ Doutora em Educação pela Universidade de São Paulo, USP, São Paulo, SP - Brasil. Coordenadora do Programa de Pós-Graduação em Educação da Universidade Católica de Santos, UNISANTOS, Santos, SP - Brasil.

E-mail: ameliasantoro@uol.com.br.

Recebido em: 01/07/2015 - Aprovado em: 03/12/2015. 
KEYWORDS: Pedagogical action research. Teacher education. Empowerment. Critical consciousness.

\section{RESUMEN}

Para volver a configurar una acción pedagógica, hacia la práctica colaborativa, es esencial que los investigadores y los profesores se involucran en procesos de mutuo aprendizaje-enseñar; dejando el extrañamiento hasta la comprensión. Se necesita tiempo y espacio para que los profesores / investigadores y sujetos de la práctica son, al mismo tiempo, los participantes y protagonistas. Considere este papel de mutua liderazgo es permitir la construcción del proceso educativo en la perspectiva de Freire, lo que es la creación de circunstancias que producen rupturas y tensiones en la conciencia ingenua, creando oportunidades para el contrapunto constructivo hacia la conciencia crítica. Este trabajo sí se basa en la investigación-acciones tomadas para este fin y que dan apoyo a la propuesta que prevé la construcción de los principios de la investigación acción pedagógica que produce el empoderamiento de los profesores, con el problema de investigación: Como maestros, desechado históricamente el papel de participantes activos e incluyó principalmente en procesos de empobrecimiento de la profesión puede encontrar la fuerza y la forma de constituirse como actores sociales, críticos y comprometidos con una nueva concepción de la vida y del mundo? Un meta-análisis llevado a cabo desde el fondo de investigación-acciones (FRANCO) a través de la hermenéutica crítica (THOUARD) indica que la organización de los dispositivos de enseñanza como la estructuración de un universo común de conocimientos desde la perspectiva de Paulo Freire puede funcionar como una base para los procesos de sensibilización. Estos dispositivos parecen acelerar una triangulación praxiológico e contribuir a la articulatión entre teorías, prácticas y valores de todos los participantes.

PALABRAS CLAVE: Investigación acción pedagógica. Formación del maestros. Empoderamiento. Conciencia crítica.

\section{INTRODUÇÃO}

Tenho afirmado em publicações anteriores (FRANCO, 2001; 2002; 2003; 2004) que as teorias educacionais, muitas vezes, não traduzem o sentido implícito das práticas cotidianas a que se reportam e, nem sempre, impregnam de compreensão o saber fazer dos educadores, dificultando sua utilização como suporte enriquecedor das ações práticas educativas, e por isso, não podem ser apropriadas ou incorporadas pelos sujeitos. Assim, essas teorias, por si, não ajudam os docentes a compreenderem suas práticas. (FRANCO, 2001, p.11)

A partir de pesquisas com a formação continuada de docentes (FRANCO, 2010; 2012 a; b; c; 2013; 2014a), posso afirmar que as teorias por si não formam o professor e tampouco a repetitiva prática docente exercida sem reflexão, sem consciência; sem crítica. Anos de docência não se transformam automaticamente em saberes da experiência! Muitas vezes, tenho compreendido em pesquisas realizadas no Observatório da Prática (FRANCO, 2010; 2013) que a prática docente se aproxima de um fazer automático, ${ }^{2}$ distante do sujeito; sem qualquer reflexão, configurando-se como uma prática alienada e alienante, para usar o conceito marxiano de alienação, como o trabalho que aliena, que escraviza, que desumaniza.

Na complexidade da interação entre formação de professores e pesquisa; entre alienação e participação; entre emancipação e empoderamento, delineia-se o objetivo deste trabalho, qual seja o de compreender quais as possibilidades que a pesquisa-ação pedagógica (PAPe) tem de produzir conhecimentos no/com o professor (e não apenas para o professor), de forma a torná-lo capaz de melhor compreender sua prática e assim poder transformá-la; bem como compreender e transformar, no coletivo, as circunstâncias que cercam essa prática, num movimento que denomino professor protagonista. ${ }^{2}$ Acredito que a proliferação de sistemas apostilados de ensino, muito vigentes atualmente no Brasil, tem contribuído
para a prática docente sem reflexão, sem autoria, sem protagonismo. 
A essa modalidade de pesquisa-ação, voltada à formação contínua de professores protagonistas, crítico-reflexivos, empoderados, capazes de transformarem a si e às suas circunstâncias, tenho denominado pesquisa-ação pedagógica (PAPe).

Acredito que toda pesquisa-ação tem caráter formativo; no entanto, no caso da pesquisa-ação pedagógica, a formação pedagógica dos sujeitos da prática passa a ser a finalidade primeira. É um trabalho participativo; colaborativo, pedagógico, entre pesquisadores e professores, na perspectiva de formação crítico-reflexiva, que, por pressuposto, reverterá na melhoria do ensino. Cumpre ressaltar que não se trata de transformar os professores em pesquisadores profissionais, mas em realizar um trabalho coletivo, que gere benefícios a ambos, ou seja: ao pesquisador, compreender a práxis docente, permitindo articular melhor teoria educacional e prática docente; e, ao professor, compreender sua prática, sua função social e política e transformar seu olhar sobre ela para, assim, poder reconstruí-la na perspectiva da formação dos alunos. Em ambos os casos, vislumbro possibilidades de retificação das teorias pedagógicas postas.

Tomo como princípios dessa forma de investigar as seguintes questões:

a) A formação de docentes no Brasil, ressalvadas boas e belas exceções, está visivelmente distante dos objetivos emancipatórios e críticos, adquirindo, um preocupante caráter tecnicista e aplicacionista; os cursos de formação inicial parecem cada vez mais apequenados, quer na direção de suas raízes epistemológicas, quer na organização e vivência de fundamentos pedagógicos; desvinculados das contradições e da complexidade, condições inerentes à profissão e à prática docente.

b) A pauperização contínua da profissionalização docente no Brasil e a precarização das condições de vida e carreira dos docentes contribuem para a falta de autonomia e para o aparecimento de uma forma contemporânea de opressão nos professores: a incapacidade de perceberem o sentido social e político de seu trabalho; tornando-se incapazes de atuar com autonomia; incapazes de perceber e transformar as condições que os oprimem.

c) A precarização das condições de trabalho e carreira impõe aos docentes a quase impossibilidade de opinar, de propor e de decidir sobre o seu próprio fazer, bem como de conviver coletivamente/colaborativamente com seus pares.

d) A ausência de fundamentos pedagógicos na sustentação e construção das práticas docentes tem produzido um esgotamento da racionalidade pedagógica, o que reverbera na ausência da esfera do diálogo, da reflexão e da crítica, reificando a situação opressora e impedindo o protagonismo docente.

e) Da confluência das condições anteriores decorre a inevitável aridez e falta de sentido e direção nas práticas pedagógicas. Considero que a prática docente, sem os fundamentos da dinâmica pedagógica a nutri-la e reconstruí-la, perde suas possibilidades de ensinar/educar/formar. 
f) Forma-se assim um círculo negativo (Figura 1), em que a educação escolar pode não mais funcionar como um dispositivo que contribua para emancipação e conscientização das gerações futuras. $\mathrm{O}$ professor não tendo condições institucionais ou pedagógicas para reinventarse, utiliza-se apenas de estratégias de sobrevivência (CHARLOT, 2005) para permanecer no trabalho. Não tem condições de investir num projeto político pedagógico e, assim, as possibilidades educativas diminuem consideravelmente.

g) No entanto, concordo com Saviani (2000), ao afirmar que, mais que constatar os danos políticos e sociais decorrentes do professor pauperizado, precarizado e proletarizado, precisamos nós, pesquisadores, dar o passo adiante, ou seja, buscar mecanismos de superação que possam, aos poucos, tensionar essa situação e indicar novos caminhos para o futuro. $\mathrm{Ou}$ mesmo, reforçando com Santos (2001), ao realçar que há apenas uma saída: "reinventar o futuro, abrir um novo horizonte de possibilidades, cartografado por alternativas radicais às que deixaram de ser" (p. 322).

h) É nessa perspectiva que proponho a PAPe: uma forma de aprendizagem/investigação coletiva, colaborativa, contínua, de forma a romper com a letargia e despersonalização dos processos de vida e formação de professores da educação básica, pública, no Brasil.

Figura 1: Ciclo negativo de formação ${ }^{3}$.

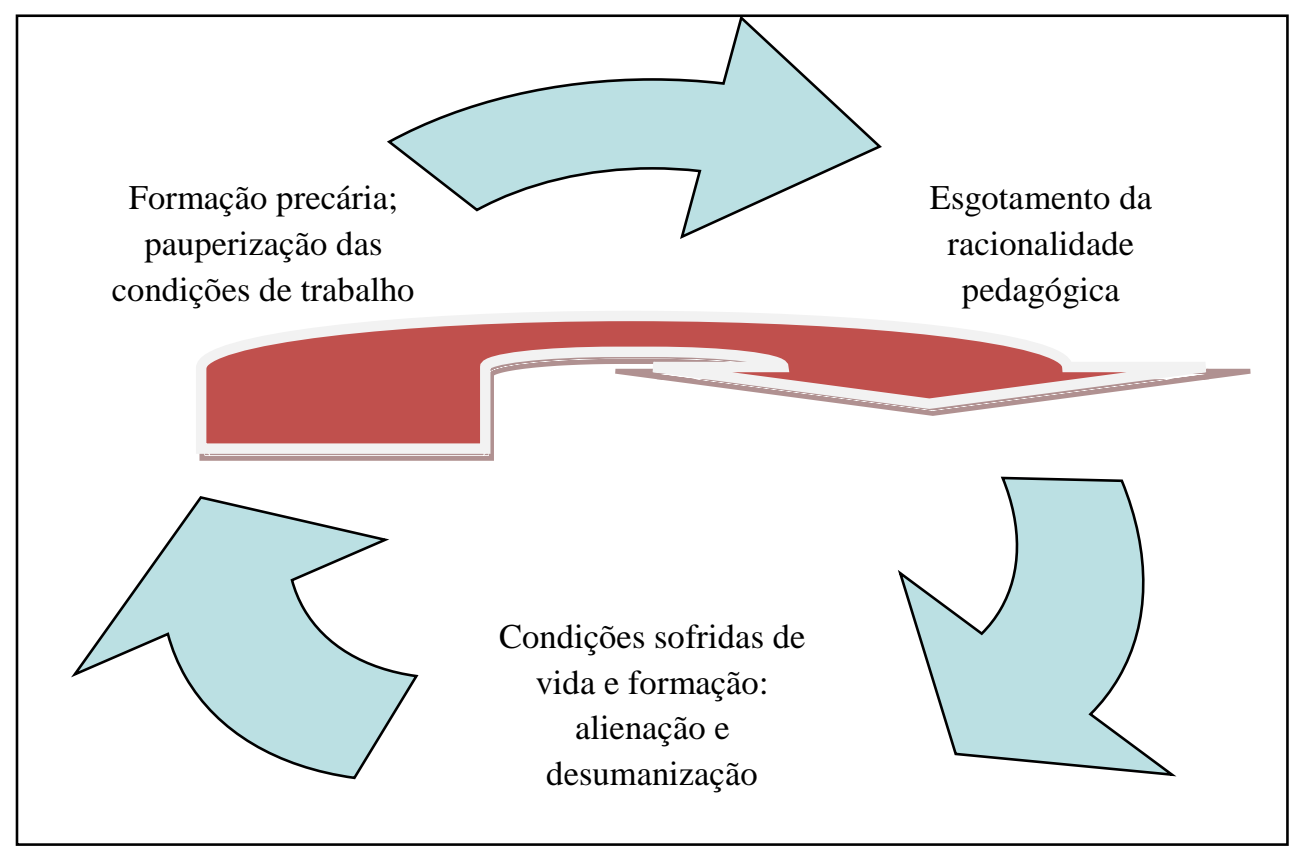

Fonte: Elaboração própria

i) A pesquisa-ação pedagógica que proponho traz uma diferença em relação à pesquisa-ação clássica, que tem por perspectiva a transformação, pelo grupo, de uma situação elegida pelo grupo. Na perspectiva da PAPe, a proposta é que os participantes, através da superação da

${ }^{3} \mathrm{~A}$ flecha vermelha pretende realçar a intervenção via PAPe com vistas à transformação/quebra do ciclo negativo. 
consciência ingênua, renovem a percepção das suas condições de vida e existência e que essa nova condição produza uma mudança de olhar do sujeito sobre a situação em que vive e que o oprime. Tenho chamado esse fenômeno de "produção de rupturas cognitivas", capazes de permitir ao professor mudar as concepções de sua profissionalidade. Como realçava Paulo Freire: o que muda o mundo são as pessoas, seus olhares sobre o mundo. É isso que se pretende: mudar o mundo da formação pela mudança nas/das pessoas que estão no mundo.

\section{PESQUISA-AÇÃO PEDAGÓGICA: MOSAICO INTERPRETATIVO}

Insiro-me na tradição dos muitos pesquisadores que me antecederam, para que, na confluência de suas contribuições, eu possa ressignificar meu trabalho com a formação continuada de docentes com pesquisas-ações e aproximar-me daquilo que tenho chamado de PAPe.

Tributo sempre a grande influência, para esta nova forma de pesquisar, denominada, desde então, pesquisa-ação, a Kurt Lewin, em 1946.

Minha concepção de pesquisa-ação está impregnada das perspectivas emancipatórias postas por Paulo Freire, em suas aulas e palestras, desde a Pedagogia do Oprimido, que passei a comungar com minha formação pedagógica desde 1968. Ao incorporar seus postulados, revelando a importância da reflexão crítica dos sujeitos sobre suas práticas e da problematização da realidade para seu enfrentamento, ficou-me evidente a presença de seus pressupostos teórico-metodológicos na consolidação da minha perspectiva de pesquisa-ação, principalmente no campo pedagógico.

Muitas influências se amalgamaram. A proposta da pesquisa-ação participativa ou pesquisaação participante (PAP) de Fals Borda no Simpósio Mundial de Cartagena, realizado em 1977, onde o autor definiu a investigacion-acción participativa como uma metodologia inserida num processo vivencial para os grupos de base, que incluía simultaneamente educação, pesquisa científica e ação política, foi um momento importante para o fortalecimento da ideia-princípio: educação como instrumento político de emancipação de povos.

Contribuindo para o fortalecimento da pesquisa-ação na prática educativa foram fundamentais as pesquisas de Laurence Stenhouse, John Elliot, Wilfred Carr e Stephen Kemmis, valorizando a postura investigativa do professor, seu protagonismo, sua voz, como elementos fundamentais para melhorar sua prática. Propostas estas que reafirmam o papel da pesquisa-ação para desencadear mudanças nas políticas e práticas institucionais que sustentam as práticas pedagógicas.

O princípio é o entrelaçamento dos sujeitos na construção da vida e dos conhecimentos que a tecem, bem expresso nas palavras de Brandão e Streck (2006):

Uma pesquisa que é também uma pedagogia que entrelaça atores-autores e que é um aprendizado no qual, mesmo quando haja diferenças essenciais de saberes, todos aprendem uns com os outros e através dos outros. (p. 13)

$\mathrm{Na}$ perspectiva apresentada, a pesquisa-ação pedagógica não se reduz a um mero procedimento de resolução de problemas práticos, mas configura-se em um meio de contribuir com a 
mudança de percepção do docente em relação às suas práticas. Gostaria de realçar que vejo três possibilidades de contribuição da pesquisa-ação nessa direção:

a) a contribuição para os processos de empoderamento dos professores, considerados como sujeitos de conhecimento e de transformação da prática;

b) a articulação da teoria, na prática e da prática, de pesquisadores e práticos, podendo funcionar como possibilidade de construção/retificação das teorias pedagógicas;

c) a produção de conhecimentos sobre a realidade educativa por meio da integração entre conhecimentos científicos e saberes práticos.

\section{PESQUISA EM EDUCAÇÃO, PESQUISA-AÇÃO E FORMAÇÃO}

Considero que para transformar uma ação pedagógica em práticas colaborativas é fundamental que pesquisadores e professores engajem-se em processos mútuos de aprender-ensinar; de estranhar-compreender.

Busca-se com a PAPe superar a perspectiva de objetos mútuos de estudo, para se adentrar num processo vivencial de vida e formação. Para tanto, é preciso tempo e espaço para que pesquisadores e sujeitos da prática sejam, ao mesmo tempo, participantes e protagonistas.

A pesquisa em educação, especialmente a referente à formação de professores, não tem dado muito realce à questão da consciência do professor como integrante de seu processo de formação. Parece-me que a categoria consciência foi substituída por algo como saberes ou competência. Não acredito na construção de saberes sem a presença consciente do sujeito no seu processo formativo. Assim, retomo o conceito freireano de consciência, como elemento fundamental da emancipação do sujeito. Transformar a consciência ingênua em consciência crítica parece ser o caminho pedagógico fundamental. Superar e transcender o senso comum; produzir novas relações com o saber da docência. (CHARLOT, 1995)

Desta forma, realço, neste trabalho, a importância da criação de dispositivos pedagógicos que funcionem como estruturantes na construção de um universo comum de conhecimentos, conforme sempre nos alertou Paulo Freire (1970). Não há participação, não há diálogo, não há reflexão, não há pesquisa-ação, se não houver um mínimo universo cultural comum entre os pesquisadores e sujeitos da prática.

Criar um universo cultural coletivo é uma tarefa fundamental do pesquisador em pesquisaação; no entanto, precisa fazê-lo na perspectiva de construção coletiva, de buscar participação, permitindo a contribuição de todos. Alerta: isso é diferente de organizar textos ou aulas para “aplicar" nos participantes! É fundamental essa postura de buscar o outro, partilhar valores e agir de modo coerente com as expressões do grupo.

Esta triangulação praxiólógica entre valores, teorias e práticas é um processo exigente que, contudo, tem fontes de inspiração muito ricas na herança pedagógica de século vinte. Uma dessas inspirações é exactamente a investigação-acção, pois ela tem um papel muito relevante na formação de profissional docente reflexivo.(OLIVEIRA-FORMOSINHO; KISHIMOTO; PINAZZA, 2007). 
Há que se recordar, conforme Contreras (1994), que a autonomia docente não é uma qualidade presente individualmente em cada sujeito, mas um processo que vai, gradativamente, garantindo a assunção, por parte do professor, de sua responsabilidade social pela condução do ensino em situações complexas, historicamente construídas e ideologicamente comprometidas. Isso só pode ser feito com um sujeito que se sinta, se aperceba como ator de sua história, um sujeito 'empoderado', habilitado ao exercício do poder que advém de suas práxis.

A questão que se coloca é: como os professores, em sua grande maioria, formados dentro dos pressupostos de uma racionalidade técnica, saberão re-construir a epistemologia que rege suas práticas e transformarem-se em sujeitos críticos de uma nova concepção de prática?

Ainda mais, perguntamos: como os professores, inseridos em um contexto social e político que desvaloriza cotidianamente sua profissão, imersos num modelo hegemônico de democracia representativa liberal (SANTOS, 2002, p.46) que desconsidera o papel da mobilização social e da ação coletiva, podem romper com tais condicionantes e fazerem-se sujeitos históricos, compromissados com uma práxis política emancipatória?

Como ainda os professores, alijados historicamente do papel de participantes ativos e inseridos em sua maioria em processos de pauperização da profissão, podem encontrar forças e caminhos para constituírem-se como atores sociais, críticos e comprometidos com uma nova concepção de vida e mundo?

Suojanen (1999), no trabalho denominado "a pesquisa-ação como estratégia para o empoderamento", analisa que o exercício criativo e transformador de uma prática profissional só pode ser exercido pelos sujeitos que têm o sentimento de controle de sua vida e de suas decisões, o que lhes dá a capacidade de sentirem-se encorajados para mudar, rever, transformar. 'Empoderar', para a autora, é um ato de construção de capacidades, de desenvolvimento pessoal e coletivo, de apreensão de crescente poder de conhecimento e controle, que vai se incorporando por meio do exercício da cooperação, do compartilhamento de saberes e do trabalho coletivo. A autora apoia-se em Wilson (1996, p.3) para afirmar que o 'empoderamento' significa comprometer-se com os objetivos comuns, assumindo riscos e demonstrando iniciativa e criatividade. Realça também que o 'empoderamento' sempre implica uma direção ética, advinda do compromisso social coletivamente assumido.

As pesquisas que tenho feito, na perspectiva de práticas colaborativas com a escola pública, permitem-me afirmar que tais práticas favorecem um alargamento nas possibilidades de crítica, de engajamento e de ressignificação dos saberes. Os benefícios e as aprendizagens são mútuos, os sentidos que se deslocam entre os pesquisadores e os práticos permitem contribuir para conhecimentos cada vez mais significativos. Acredito ser esse o caminho a ser perseguido para a rigorosidade na pesquisa em educação e para a credibilidade de processos de formação de docentes.

A grande questão que se coloca ainda é: como buscar a participação de sujeitos, professores, que não se sentem empoderados para participar? Como transformar uma participação marginal, aderente e cativa em uma participação colaborativa, crítica, coletiva? 
Considero que só a ação docente, realizada como prática social pode produzir saberes, saberes disciplinares, saberes referentes a conteúdos e sua abrangência social, ou mesmo saberes didáticos, referentes às diferentes formas de gestão de conteúdos, de dinâmicas da aprendizagem, de valores e projetos de ensino.

No entanto, a possibilidade de produção de conhecimentos sobre a prática requer que o sujeito se coloque em condição de dialogar com as circunstâncias, de compreender as contradições, de articular teoria e prática. Só com esse sujeito atuante é que se pode falar em saberes pedagógicos, como a possibilidade de criar na prática, conhecimentos sobre a condução, a criação e a transformação dessas mesmas práticas.

O saber pedagógico só pode se constituir a partir do próprio sujeito, que deverá ser formado como alguém capaz de construção e de mobilização de saberes. A grande dificuldade em relação à formação de professores é que, se quisermos ter bons professores, teremos que formá-los como sujeitos capazes de produzir ações e saberes; conscientes de seu compromisso social e político.

A realidade educacional e diversas pesquisas estão indicando que não funciona formar professores como objetos dotados de habilidades e competências instaladas de fora para dentro, sob forma de fazeres que foram criados por especialistas, que nada significam na hora da prática. Sintetizando com a afirmativa de Imbert (2003): o movimento em direção ao saber e à consciência do formador não é outro senão o movimento de apropriação de si mesmo. ( p.27).

Para a construção desse movimento de apropriação de si, é fundamental uma pesquisa que trabalhe com a formação do sujeito e que lhe dê condições de relacionar-se produtivamente com seu contexto. Assim, pesquisadores como Morin (1985); Lavoie, Marquis e Laurin (1996); FRANCO (2003; 2005; 2008; 2014a) consideramos que a pesquisa-ação de perspectiva formativa deve absorver algumas perspectivas:

a) integração de pesquisadores e participantes, com finalidades formativas e emancipatórias, vinculada a compromissos sociais com o coletivo, ou seja, ela deve emergir da complexidade da práxis;

b) mobilização e potencialização de mecanismos cognitivos e afetivos dos sujeitos, na direção de irem assumindo, com autonomia, seu processo de autoformação;

c) consideração da complexidade dialética do processo formativo o que implica uma flexibilidade criativa que evolua de acordo com a imprevisibilidade do contexto; que ofereça espaço ao não previsto, ao novo e emergente, ao mesmo tempo, em que ofereça possibilidade de inteligibilidade aos conhecimentos que vão emergindo no processo;

d) construção contínua e dialógica do diálogo, oferecendo direção e sentido ao desenvolvimento pessoal de cada sujeito; abrindo espaços de movimento livre na perspectiva de Lewin, 1946 para diálogos com a prática docente, quer a exercida por eles próprios, quer a exercida por colegas e, nesse diálogo, ir construindo um olhar crítico e reflexivo sobre as mesmas; propiciando possibilidades de dialogar com os contextos de sua prática, os condicionantes de sua profissão. 


\section{DISPOSITIVOS PEDAgógICOS PARA CONSTRUÇÃO DE UNIVERSO COMUM COLETIVO: O DESENCADEAR DE PROCESSOS PARTICIPATIVOS}

O grande problema de introduzir a pesquisa-ação na prática cotidiana, sempre foi o início do processo: como falar de pesquisa, ou como introduzir procedimentos de pesquisa, ou ainda, como envolver sujeitos em situação de pesquisa, em um ambiente institucional que não considera a pesquisa como um elemento fundamental? Reitero a necessidade de estratégias pedagógicas, que tenho denominado de dispositivos pedagógicos, que tenham o intuito de desencadear processos participativos. No entanto, ao trabalhar com professores do ensino fundamental da rede pública, percebo que há uma grande fragilidade na autonomia docente e uma grande solidão em suas práticas. Tenho observado que, sozinhos os professores não criam essa condição, pois nem sempre o ambiente institucional, oferece disponibilidade para isso. Desta forma recorri a Paulo Freire e suas estratégias pedagógicas para tentar retirar o oprimido de seu ciclo de opressão e também recorri a Bernard Charlot e seus estudos e pesquisas sobre a construção de relações com o saber, com populações com pouco acesso à cultura sistematizada. Assim, realço alguns desses dispositivos que tenho utilizado para iniciar propostas de pesquisa-ação:

\section{Pesquisa e ação: lendo, escrevendo, pesquisando o mundo}

Tomando por princípio norteador o delineamento do "Método Paulo Freire", o desenvolvimento do Círculo de Cultura consiste de três momentos: a) a investigação temática, pela qual os componentes do círculo e o pesquisador buscam, no universo vocabular dos participantes e da sociedade onde vivem, as palavras e temas centrais de suas biografias; b) a tematização, mediante a qual codificam e decodificam esses temas; momento em que buscam o seu significado social e estabelecem novas relações com o saber, criando sentido e tomando consciência do mundo vivido; c) a problematização, por meio da qual buscam superar a concepção mágica, ingênua, limitada do mundo, por uma visão crítica, partindo para a possibilidade de transformação do contexto vivido.

Constituindo uma estratégia da educação libertadora, o Círculo de Cultura é um lugar onde todos têm a palavra, onde todos leem e escrevem o mundo. É um espaço de trabalho, pesquisa, exposição de práticas, dinâmicas, vivências que permitem a elaboração coletiva do conhecimento.

Os princípios deste método freireano têm funcionado bem em trabalhos de formação continuada com professores da educação básica: considerando-se que os professores estão se sentindo fragilizados com a agudez das contradições da escola brasileira; com a complexidade das relações sociais que aí se estabelecem e com a incapacidade teórico-prática de atuarem na situação, esse espaço tempo de reflexão permite uma nova perspectiva de situação experiencial. Os textos prontos que recebem para servir de guias de aula, dentro da perspectiva de ensino apostilado, acabam induzindo-os a trabalharem com o roteiro pronto e abrindo mão da possibilidade de criarem meios e formas didático-pedagógicas para lidar com a situação. Em pesquisas que tenho realizado com a escuta sensível, convido-os a falarem dos sentimentos e situações que vivenciam, percebo que os docentes sentem-se acolhidos; quando se deparam com o instrumental da teoria, discutindo os problemas que enfrentam, utilizando-os como ferramentas para compreenderem melhor a situação 
em que se encontram, passam, gradativamente, a incorporar algumas indagações e estabelecem algumas trocas produtivas com seus pares. Costumo, após o tempo da escuta instigá-los a escreverem suas vivências, suas compreensões e suas dúvidas e essa escrita tem permitido que estabeleçam um contato maior com suas dificuldades e anseios e se percebam, ainda que de modo incipiente, como autores de sua prática. (FRANCO, 2012c)

Considero que as atividades que compõem a formação resultam melhor quando envolvidas em processos investigativos. Ao iniciarem-se no olhar investigativo e começarem a se articular como pesquisadores em ação, passam a problematizar a realidade e a buscar alternativas de pensamento e reflexão. Ao pesquisador cabe a escolha de textos que facilitem a tarefa de pesquisar a realidade envolvida, analisando e contextualizado conceitos e práticas. É sabido que uma das melhores formas de envolver o sujeito nas atividades é mobilizá-lo com perguntas, pesquisas, buscas e sínteses. (FREIRE, 1979; CHARLOT, 2013; PIMENTA, 2002; FRANCO, 2013). Assim, por meio da PAPe, os encontros transformam-se em oficina de busca e indagação, produzindo novos olhares sobre a prática e permitindo aprendizagens mais consistentes que aquelas produzidas em ambientes de transmissão de conteúdos.

\section{Pesquisa e ação: dialogando e criando novos sentidos}

Paulo Freire, em toda sua obra, sempre se referiu à necessidade de se estabelecer entre alunos e professores um universo comum de conhecimento, a partir do qual, poder-se-ia estabelecer as bases de um diálogo na perspectiva do logos que vai então se estruturando e se construindo. Nesse processo, os sentidos vão sendo criados e transformados, conforme Charlot (2005). Assim, considero a importância de fomentar processos dialogais efetivos. Historicamente, esse sentido de diálogo foi muitas vezes apropriado como senso comum. Há que se recordar que o diálogo precisa estar voltado à construção do conhecimento. Lembra-nos Freire que para aprender é preciso existir, e existir ultrapassa viver porque é mais do que estar no mundo. É estar nele e com ele. E é essa capacidade ou possibilidade de ligação comunicativa do existente com o mundo objetivo, contida na própria etimologia da palavra, que incorpora ao existir o sentido de criticidade que não há no simples viver. "Transcender, discernir, dialogar (comunicar e participar) são exclusividades do existir. O existir é individual, contudo só se realiza em relação com outros existires. Em comunicação com eles"(FREIRE, 1979, p. 57). Essa exigente proposta de diálogo como criticidade é fundamental para superar o sentido banal de diálogo como conversa. Em sala de aula, o diálogo adquire a perspectiva de problematização da realidade e de crítica. Essa é a dimensão que precisa ser buscada, a superação do empírico pelo concreto, o que se faz pelo diálogo e pela teoria. Esse processo cria sentido e mobiliza para a ação. Afirma Freire, em 1979, que uma educação dialogal e crítica pode conduzir a uma transitividade crítica voltada para a responsabilidade social e política, e esta transitividade se caracteriza "pela profundidade na interpretação dos problemas. Pela substituição de explicações mágicas por princípios causais. [...]. Pela prática do diálogo, e não da polêmica”. (p.85). Essas questões são fundamentais como ingredientes à formação docente. 
Pesquisa e ação: substituir fórmulas mágicas por processos de reflexão

É difícil o início da reflexão pelos docentes em relação às próprias práticas. Tenho me utilizado da autoscopia ou mesmo das narrativas das aulas. A autoscopia traz ao sujeito um novo ângulo de sua prática; as narrativas abrem o horizonte para organizar suas ideias e recompor os sentidos. Ambas aproximam o professor aos processos de reflexão, de uma práxis mais comprometida. Costumo dizer que aos poucos o professor parece se aproximar de sua prática, estranhá-la, compreendê-la, e pensar em meios de transformação. Concordo com Freire, quando percebo o professor realizando rupturas cognitivas em suas concepções pedagógicas: a práxis, "como reflexão e ação dos homens sobre o mundo para transformá-lo. Sem ela é impossível a superação, da contradição opressor-oprimido”. (1984, p. 38)

Realço sempre que a apreensão aligeirada do conceito reflexão tem dificultado a práxis decorrente e sua utilização tem sido banalizada, como bem já sinalizou Pimenta e Ghedin (2002). A reflexão, quando distante do conteúdo crítico-político, vira mais um pragmatismo, o que impede de funcionar como uma proposta contra hegemônica, frente ao pragmatismo e ao tecnicismo que têm impregnado as práticas educativas e sociais.

Nas experiências com PAPe, tenho percebido que é preciso refletir a partir de um saber comum, de um saber contextualizado, sobre o papel social e político da educação e do trabalho docente. Esse movimento da epistemologia reflexiva da prática, dentro da racionalidade crítica, tal qual proposta por Carr e Kemmis (1995), e desenvolvida, dentre outros por Pimenta (2002), inova e organiza possibilidades de ruptura com algumas circunstâncias da cultura profissional institucionalizada que limitam o exercício e o desenvolvimento da autonomia intelectual dos docentes. Por isso sua prática, via PAPe, é estratégica para a tomada de consciência do professor e para contribuir para a superação de condições inadequadas do trabalho do professor.

Vale a pena refletir com Imbert (2003) sobre a distinção que faz entre prática e práxis, e atentando para a questão da autonomia e da perspectiva emancipatória, inerente ao sentido de práxis. Distinguir práxis e prática permite uma demarcação das características do empreendimento pedagógico. Há, ou não, lugar na escola para uma práxis? Ou será que, na maioria das vezes, são simples práticas que nela se desenvolvem, ou seja, um fazer que ocupa o tempo e o espaço, visa a um efeito, produz um objeto (aprendizagem, saberes) e um sujeito-objeto (um escolar que recebe esse saber e sofre essas aprendizagens), mas que em nenhum momento é portador de autonomia. (2003, p. 15). O exercício da práxis requer processos de conscientização do professor sobre o papel que desempenha na sala de aula, no mundo, na vida dos alunos. Somente um professor consciente dessas circunstâncias pode produzir mudanças e novas perspectivas na vida dos alunos. 
Pesquisa e ação: A perspectiva de produção de rupturas cognitivas (novas dinâmicas compreensivas)

Um ensino que proceda à mediação reflexiva entre os valores e a cultura que a sociedade dissemina cria mais significado aos sujeitos que dele participam. Escrevi em 2001 (FRANCO, 2001) uma proposta de procedimento de pesquisa que elabora uma releitura da metodologia da história de vida enfocando seu caráter emancipatório e, principalmente, aliando a tarefa investigativa com a formação de professores reflexivos.

Essa proposta emergiu de experiências de formação contínua com professores de uma escola pública e baseia-se no pressuposto de que o conhecimento dos processos de profissionalização permite ao professor apropriar-se dos canais de diálogo entre a realidade vivida e interpretada, ampliando as possibilidades de compreensão objetiva dos mecanismos construtores de sua prática docente. Esta metodologia transforma-se em instrumento de formação, à medida que insere o sujeito numa nova dinâmica compreensiva que incorpora novos sentidos à sua ação docente e produz movimentos de reflexão, reconfigurando os contextos de sua existência e integrando o professor em um novo "círculo compreensivo", o que facilitará a construção de novas "dinâmicas de autoformação participada" (NÓVOA, 1992).

Tenho observado em contínuos trabalhos com PAPe que a prática reflexiva, que daí decorre, demanda tempo e condições para emergir, necessitando de algumas condições, tais como:

a) A prática reflexiva, como uma proposta política pedagógica, necessita, para se efetivar, de uma cultura que considera a dialeticidade como forma de construção da realidade histórica; como princípio na formação e desenvolvimento do ser humano; como lógica na compreensão e interpretação dos fatos educativos; como estratégia para construção de consensos coletivos.

b) A prática reflexiva, para se exercer em sua integralidade, necessita de espaços institucionais, não excessivamente burocratizados, nem de excessivo controle, mas, ao contrário, onde exista uma cultura do diálogo, da intercomunicação, onde se valorize os comportamentos colaborativos, solidários, críticos, intersubjetivos.

c) A prática reflexiva, para produzir as transformações decorrentes de seu exercício cotidiano, precisa se consolidar no sentido de não aceitação de verdades prontas, de soluções definitivas; há que se trabalhar na construção constante das sínteses provisórias; revendo continuamente os fundamentos do compromisso social da educação, elaborando vínculos processuais entre valor/ação/novas valorações, na construção daquilo que tenho chamado de construção contínua de "novos círculos compreensivos".

d) A prática reflexiva é uma capacidade histórica e, portanto, deve ser desenvolvida e atualizada, necessitando para isto de parceiros com diferentes olhares. Os professores não podem, sozinhos, descobrir o caminho deste processo, pois correm o risco de não elaborarem um desenvolvimento em espiral (espirais cíclicas) e permanecerem, corporativamente, reforçando e justificando as próprias referências. A PAPe tem demonstrado sua possibilidade ao quebrar o círculo negativo 
mantido por estratégias de sobrevivência (CHARLOT, 2005) utilizadas pelos professores frente suas dificuldades e impasses.

Uma proposta interessante e necessária é a presença contínua, crítica e construtiva do pesquisador educacional, realizando pesquisas-ações pedagógicas, e desta forma, fertilizando, referenciando e aprendendo-se com todos, a partir de processos críticos desencadeados pela consciência que a prática docente refletida pode trazer.

\section{CONSIDERAÇÕES E PERSPECTIVAS}

Todo projeto para a formação de professores supõe uma concepção sobre a função da profissão docente. O professor é um profissional do ensino. Qual é a natureza desse trabalho? O que significa formar o professor para exercer a profissão de ensinar? São perguntas que diferentes projetos e perspectivas de formação têm procurado responder, contrapondo-se à racionalidade técnica, especialmente desde que Schön, na década de 1980, demonstrou a insuficiência desse paradigma de formação profissional universitária ${ }^{4}$.

A racionalidade técnica, de fundamentação positivista, postula um valor determinante para a investigação científica sobre as situações práticas. Os modelos de formação de professores baseados nessa perspectiva investem, em primeiro lugar, na aprendizagem dos fundamentos dos conhecimentos científicos para que, depois, os professores possam aplicá-los de acordo com seus princípios ou regras. Essa forma de conceber a formação tem contribuído para criar hierarquias acadêmicas e sociais entre as ciências que se dedicam à pesquisa do fenômeno educativo e entre as pessoas que nele trabalham. Assim, no âmbito da cultura de formação docente universitária, tem se verificado, historicamente, uma naturalização da divisão entre quem produz e quem consome o conhecimento educacional e um distanciamento entre a pesquisa educacional denominada acadêmica e as necessidades sentidas pelos professores e suas escolas.

Uma consequência dessa divisão e desse distanciamento tem-se convertido em um tema clássico da Educação: a desarticulação entre teoria e prática na formação docente. São situações geradas, cristalizadas numa cultura profissional e que eu conceituo como saber pedagógico colonizado. Ou seja, saberes construídos por outros e que não fazem sentido à prática do professor, mas que mesmo assim são utilizados para referendar procedimentos e ações didático-pedagógicas.

O contraponto desta racionalidade instaura-se na discrepância que vai se instalando entre os conhecimentos científicos ensinados por meio da formação e os que realmente praticam e vivem os professores em seu campo profissional. Atualmente há um discurso, banalmente instituído, que

\footnotetext{
${ }^{4} \mathrm{Na}$ década de 1980, Donald Schön, ao estudar a formação profissional universitária utilizando como referência o curso de arquitetura, denunciou sua vinculação à racionalidade técnica e propôs a formação de profissionais reflexivos, produtores de saberes e conhecimentos sobre sua prática. Essa proposta desencadeou uma crítica generalizada à racionalidade técnica e teve grande repercussão nas propostas e pesquisas sobre formação de professores. A esse respeito, consultar, dentre outros: Nóvoa, 1992; Pérez-Goméz, 1992; Zeichner, 1993; Sacristán e Gómez, 1998 ; Garcia, 1992, 1999, Geraldi, C, 1998; Lipovetsky, 2001; Pimenta e Ghedin, 2002; Rosa, 2003.
} 
considera que há excesso de teorias na formação dos docentes ${ }^{5}$. No entanto, sabe-se que a prática, sem a fundamentação da teoria, que a transforma e é por ela transformada, deixa de ser uma prática e traveste-se em uma mera ação mecânica, rotineira, sem o suporte da reflexão, que poderia fazer a mediação entre a teoria e a prática que dela emana.

Contreras (1994) ironiza a situação de que, ao retirar a perspectiva teórico-reflexiva da formação de professores, como querem os saudosistas do positivismo, os professores se tornem mero reprodutores de ação; sujeitos que não replicam; não criam; não perguntam. Em vista disso, argumenta o autor, a solução proposta pelos que não acreditam na necessidade de teorias, de reflexões na formação, seria construir currículos à prova de professores, isto é, currículos que neutralizassem as resistências às inovações educacionais e às divergências sobre os significados dos conhecimentos científicos ensinados. Concordando com o autor, realço que a alternativa é outra, e passa pela compreensão de que o ensino se move por uma racionalidade diferente da que vem orientando a formação profissional dos professores. É nessa direção que a pesquisa-ação vai se organizando como metodologia para articular o sujeito com suas circunstâncias e assim, propiciar a construção de seus saberes de forma critica e mais emancipatória.

Essa compreensão coloca a necessidade de se insistir na formação de professores como profissionais que exercem um trabalho de natureza intelectual, cujas implicações morais e éticas demandam uma postura de autonomia, entendida como um processo de construção permanente de emancipação pessoal e coletiva, bem como, das limitações das atuais condições institucionais e sociais de realização do ensino. Essa aspiração para a formação docente fundamenta-se na concepção de professor como intelectual crítico, formulada por muitos pesquisadores com realce aos estudos de Contreras (2002) a partir de uma revisão crítica do conceito de professor reflexivo de Schön (2000); dos estudos de Giroux (1997) sobre a pedagogia crítica, com realce à concepção de professor como intelectual transformador e apoiada na proposta de reflexão crítica de Smyth (1992), os estudos de Carr e Kemmis (1988); de Kincheloe (1997) que enfatiza o compromisso político na formação do professor e a necessidade de uma pesquisa-ação crítica; e, desde sempre, de Paulo Freire $(1979 ; 1999)$ ao realçar a importância da consciência crítica como instrumento de emancipação; dentre outros.

Entender o ensino como prática social implica inseri-lo num contexto de atuação mais amplo, no qual estão envolvidas múltiplas conjunções culturais, históricas, ideológicas, entre outras. Significa entendê-lo, também, como prática profissional pública exercida na relação com os outros. Por isso, a ideia de autonomia como processo em construção, depende de que esta possa se constituir na relação com as pessoas implicadas na prática educativa.

A pesquisa-ação se propõe a ser um processo que forma os sujeitos para conviver criticamente na articulação de discursos instituídos e ação, o que pode possibilitar a revisão de teorias que não mais se justificam e práticas que já não criam sentidos. BARBIER (2003, p.48-48) afirma que "mudar é aquilo por meio do qual o reprimido sai de seu ciclo de repetições, e assim, o autor referenda, em parte, essa compreensão da ação pedagógica como práxis; ou seja, em processos

${ }^{5}$ http://www1.folha.uol.com.br/educacao/2013/08/1321237-formacao-do-professor-tem-muita-teoria-e-poucapratica.shtml 
de formação o importante é produzir a dissonância entre o pré-estabelecido e o possível; entre o sujeito e sua realidade circundante; entre o discurso internalizado e o discurso necessário.

Nas constatações do gradativo esgotamento da racionalidade pedagógica, que se tem instaurado como decorrência, dentre outros fatores, da mercantilização da formação de professores, verificada em diferentes instâncias ${ }^{6}$, é que se propõe a pesquisa-ação pedagógica como uma instância crítica para a criação de circunstâncias que produzam rupturas e tensões nas condições atuais de formação e prática docente, oferecendo aos docentes condições de algum empoderamento que lhes permita reagir criticamente aos impactos das políticas de formação conduzidas/geridas/propostas por mecanismos internacionais ${ }^{7}$, que têm tirado cada vez mais o protagonismo dos docentes.

Ninguém terá a liberdade de procurar um ensino melhor e uma educação mais sólida [...] até que a camisa-de-força intelectual exercida pelo cartel de formação de professores seja rompida. (Holland 2004,apud Zeichner, 2013)

Acredito, apoiando-me, entre outros, em MARX (1987) ou VÁZQUEZ (2002), no poder das contradições que alavancam tensões nas racionalidades postas; em especial nesta, fruto do projeto neoliberal a que já me referi, que submete o professor a condições degradantes; pois se sabe que toda racionalidade é uma construção social amalgamada por relações recíprocas e contraditórias entre condições objetivas da realidade social e representações socialmente construídas; o que sempre permitirá um espaço de reação: o sujeito alienado não é totalmente anulado pelo regime que o aliena. Há espaços para reações; há espaços para renascimentos! Como realçou MARX-ENGELS (1844/2003),

A história não faz nada, não 'possui imensas riquezas', não 'financia batalhas'. É o homem real, o homem vivo quem faz tudo isso, quem possui e combate; a 'história' não é, como se tem pensado, uma pessoa em si, usando o homem como um meio para atingir os seus (dela) próprios fins; a história não é nada além da atividade do homem perseguindo os seus (dele) fins. ${ }^{8}$

Assim, aposta-se na possibilidade de que, a pesquisa-ação pedagógica configure-se como uma opção metodológica e como tal, epistemológica, que possa contribuir para uma articulação mais significativa entre teorias, práticas e valores entre todos os participantes de atividades educativas, favorecendo a construção de uma relativa e necessária autonomia pedagógica, que possa contraporse a este preocupante "cartel de formação professores", referido por HOLLAND (2004) e bastante perceptível já em nossa realidade educacional.

\footnotetext{
${ }^{6}$ Vide para aprofundamento: ZEICHNER, K. Políticas de Formação de professores nos Estados Unidos: como e por que elas afetam vários países no mundo. Belo Horizonte: Autêntica, 2013.

${ }^{7}$ Para aprofundar essa questão vide toda bibliografia de FREITAS, Luís Carlos. Disponível em http://avaliacaoeducacional.com/author/freitaslc/

${ }^{8}$ Texto de Marx, escrita com Engels, na obra Sagrada Família, cap. VI e retirada da pagina de Andy Blunden na rede: http://home.mira.net/ andy/
} 


\section{REFERÊNCIAS}

BARBIER, René. A pesquisa-ação. Brasília: Plano, 2002.

BORDA, Orlando Fals. Investigating reality in order to transform it the Colombian experience.

Dialectical Anthropology, v. 04, n. 01, p. 33-55. mar. 1979. Disponível em:

< https://goo.gl/X8MmMM>. Acesso em: 01 jul. 2015. ISSN 1573-0786.

BRANDÃO, Carlos Rodrigues; STRECK, Danilo Romeu. Pesquisa participante: o saber da partilha. Aparecida: Ideias \& Letras, 2006.

BRANDÃO, Carlos Rodrigues; STECK, Danilo Romeu. Participar-pesquisar. In: BRANDÃO, Carlos Rodrigues (Org.). Repensando a pesquisa participante. São Paulo: Brasiliense, 1999, p. 0714.

CANDAU, Vera Maria. Educação em Direitos Humanos no Brasil: realidades e perspectives. In: CANDAU, Vera Maria; SACAVINO, Suzana (Org.). Educar em direitos humanos, construir democracia. Rio de Janeiro: DP\&A, 2000, p.72-99.

CARR, Wilfred; KEMMIS, S. T. Teoria crítica de la enseñansa. Barcelona: Martinez Roca, 1988.

CARR, Wilfred; KEMMIS, S. T. Becoming critical education; knowledge and action research. London: The Palmer, 1995.

CHARLOT, Bernard. Da relação com o saber às práticas educativas. São Paulo. Cortez. 2013.

CHARLOT, Bernard. Les sciences de l'éducation; un enjeu, um défi. Paris: ESF, 1995.

CHARLOT, Bernard. Relação com o saber, formação de professores e globalização: questões para a educação hoje. Porto Alegre: Artmed, 2005.

CONTRERAS, José Domingo. Autonomia de professores. São Paulo: Cortez, 2002.

CONTRERAS, José Domingo. La investigación en la acción. Cuadernos de Pedagogía, Barcelona, ES, p. 07-19. abr. 1994.

ELLIOT, Jhon. La investigación-acción en educación. Madri: Morata, 1990. Disponível em: <http://goo.gl/B8vj4Q>. Acesso em: 01 jul. 2015.

FRANCO, Maria Amélia Santoro; PIMENTA, Selma Garrido (Org.). Pesquisa em Educação: possibilidades investigativo-formativas da pesquisa-ação. 2. ed. São Paulo: Loyola, 2010.

FRANCO, Maria Amélia Santoro; BETTI, Mauro. Verbete: pesquisa-ação. In: GONZÁLEZ; FENSTERSEIFER. Critical dictionary of physical education. 3. ed. Ijuí: Editora Inijuí, 2014, p. 502-510. 
FRANCO, Maria Amélia Santoro; PIMENTA, Selma Garrido. Profissionalization et travail enseignant: la recherche-action collaborative. In: COLLOQUE INTERNATIONAL, 21., 2011, Lyon, França. Anais eletrônicos... Lyon, 2011. Disponível em: 〈http://goo.gl/3n9nM5 $\rangle$. Acesso em: 01 jul. 2015.

FRANCO, Maria Amélia Santoro. Observatório da prática docente: um espaço para compreensão/transformação da prática docente. Projeto de pesquisa e Relatório de Pesquisa Capes/CNPQ. São Paulo. 2007; 2011b; 2013. Disponível em: 〈http://goo.gl/y9Ysy2>. Acesso em: 01 jul. 2015.

FRANCO, Maria Amélia Santoro; LISITA, Verbena Soares de Sousa. Action research: limits and possibilities in teacher education. British Education Index, Brotherton Library - University, p. 0115. 2004. Disponível em: 〈http://goo.gl/u5nFnV〉. Acesso em: 01 jul. 2015.

FRANCO, Maria Amélia Santoro. Por um currículo de formação de pedagogos: indicativos. In: Pimenta, Selma Garrido. (Org.). Pedagogia e pedagogos: caminhos e perspectivas. São Paulo: Cortez, 2002, p. 99-128.

FRANCO, Maria Amélia Santoro. A pedagogia como ciência da Educação. Campinas: Papirus, 2003.

FRANCO, Maria Amélia Santoro. A pedagogia como ciência da Educação: por entre praxis e epistemologia. Tese (Doutorado em Educação) - Faculdade de Educação, Universidade de São Paulo, São Paulo, SP, 2001.

FRANCO, Maria Amélia Santoro. A pedagogia da pesquisa-Ação. Educação e Pesquisa, São Paulo, SP, v. 31, n. 03, p. 483-502. set./dez.2005. Disponível em: 〈http://goo.gl/mBbgRd >. Acesso em: 01 jul. 2015. ISSN 1678-4634.

FRANCO, Maria Amélia Santoro. Pedagogia como ciência da educação. Campinas: Cortez, 2008.

FRANCO, Maria Amélia Santoro. Pedagogia e prática docente. São Paulo: Cortez, 2013.

FRANCO, Maria Amélia Santoro. Pesquisa-ação e prática docente: possibilidades de descolonização do saber pedagógico. In: Diálogos interculturais: descolonizar o saber e o poder. Florianópolis: UFSC, 2009, p.1-21.

FRANCO, Maria Amélia Santoro. Pesquisa-ação: a produção partilhada de conhecimento In: Pesquisa-ação: uma alternativa à práxis. Uberlândia: UDUFU, 2012b, p. 51-70.

FRANCO, Maria Amélia Santoro. Pesquisa-ação: balizando princípios metodológicos. In: STRECK, Danilo Romeu; SOBOTTKA, Emil Albert; EGGERT, Edla. (Org). Pesquisa-ação e pesquisa participante em diálogo internacional. Curitiba: CRV, 2014a.

FRANCO, Maria Amélia Santoro. Práticas colaborativas na escola: as possibilidades da pesquisaação pedagógica. In: TOMASIELLO, Maria Guiomar Carneiro; MARIN, Alda Junqueira; PIMENTA, Selma Garrido et al. (Org.). Didática e práticas de ensino na realidade escolar contemporânea: constatações, análises e proposições. Araraquara: Junqueira e Marin, 2012c, p. 883-900. 
FRANCO, Maria Amélia Santoro. Práticas pedagógicas nas múltiplas redes sociais. In: LIBÂNEO, José Carlos; ALVES, Nilda. Doze temas da pedagogia: as contribuições do pensamento em currículo e em didática. São Paulo: Cortez, 2012d, p. 169-189.

FRANCO, Maria Amélia Santoro; NOVAES, Marcos Bidart; PONTES, Rosana Aparecida Ferreira. Facing resignation and silence: a transforming action-research experience in Brazil. International Journal of Action Research, Alemanha, v. 05, n. 02. 2009. Disponível em: 〈http://goo.gl/VCB7tj>. Acesso em: 01 jul. 2015. ISSN 1861-9916.

FREIRE, Paulo. Ação cultural para a liberdade. Rio de Janeiro: Paz e Terra, 1979.

FREIRE, Paulo. Criando métodos de pesquisa alternativa: aprendendo a fazê-la melhor através da ação. In: BRANDÃO, Carlos Rodrigues (Org.). Pesquisa participante. São Paulo: Brasiliense, 1999 , p. 34-41.

FREIRE, Paulo. Conscientização: teoria e prática da libertação: uma introdução ao pensamento de Paulo Freire. São Paulo: Cortez, 2008.

FREIRE, Paulo. Educação como prática da liberdade. 27. ed. Rio de Janeiro: Paz e Terra, 2003.

FREIRE, Paulo. Pedagogia do oprimido. Rio de Janeiro: Paz e Terra, 1984; 2005.

GARCIA, Carlos Marcelo. O pensamento prático do professor - a formação do professor como profissional reflexivo. In: NÓVOA, António. Os professores e sua formação. Porto: Porto Editora, 1992.

GARCIA, Carlos Marcelo. Formação de professores - Para uma mudança educativa. Porto: Porto, 1999.

GERALDI, Corinta Maria Grisolia; FIORENTINI, Dario; PEREIRA, Elisabete Monteiro de Aguiar (Org.). Cartografias do trabalho docente. Campinas: Mercado das Letras, 1998.

GIROUX, Henry. Os professores como intelectuais: rumo a uma aprendizagem crítica da aprendizagem. Porto Alegre: Artmed, 1997.

GÓMEZ, Pérez. A função e a formação do professor no ensino para a compreensão: diferentes perspectivas. In: SACRISTÁN, Gimeno; GÓMEZ, Pérez. Compreender e transformar o ensino. Porto Alegre: Artes Médicas, 1998.

GÓMEZ, Pérez. O pensamento prático do professor: a formação do professor como profissional reflexivo. In: NÓVOA, António. (Org.). Os professores e a sua formaçãa. Portugal: Dom Quixote, 1992.

IMBERT, Francis. Para uma práxis pedagógica. Brasília: Plano Editora, 2003.

KEMMIS, Stephen. Action research. International Encyclopedia of Education. Oxford: Pergamon, 1984, p. 35-42. 
KINCHELOE, Joel. A formação do professor como compromisso político: mapeando o pósmoderno. Porto Alegre: Artmed, 1997.

LAVOIE, L.; MARQUIS, D.; LAURIN, P. La recherché-action: théorie et pratique. Canadá: Presses de l'Université du Québec, 1996.

LEWIN, Kurt. Problemas de dinâmica de grupos. São Paulo: Cultrix, 1970.

LIMA, Lauro de Oliveira. Método Paulo Freire: processo de aceleração de alfabetização de adultos. In: LIMA, Lauro de Oliveira. Tecnologia, educação e democracia. Rio de Janeiro: Civilização Brasileira, 1979.

LIPOVETSKY, Noêmia. Ensino e formação de professores: as representações de professores do curso de pedagogia da Faculdade de Educação da UFG. 2001. 187 f. Dissertação (Mestrado em Educação) - Faculdade de Educação, Universidade Federal de Goiás, Goiânia, GO, 2001.

MARX, Karl; ENGELS, Friedrich. A sagrada família. São Paulo, Boitempo, 2003.

MORIN, André. Recherche-action en éducation: de la pratique à la théorie. Rapport: Canadá: Université de Montreal, 1985.

NÓVOA, António. (Org.). Os professores e a sua formação. Portugal: Dom Quixote, 1992.

OLIVEIRA-FORMOSINHO, Júlia., KISHIMOTO, Tizuko Morchida; PINAZZA, Monica Appezzato (Orgs.). Pedagogia(s) da infância: dialogando com o passado construindo o futuro. Porto Alegre: Artmed. 2007.

PIMENTA, Selma Garrido; GHEDIN, Evandro (Org.). Professor reflexivo no Brasil: gênese e crítica de um conceito. 8. ed. São Paulo: Cortez, 2012.

PIMENTA, Selma Garrido. Professor: formação, identidade e trabalho docente. In: PIMENTA, Selma Garrido. (Org.). Saberes pedagógicos e atividade docente. São Paulo: Cortez, 1999, p. 1534.

ROSA, Dalva Gonçalves. Investigação-ação colaborativa sobre práticas docentes na formação continuada de formadores. 2003. $201 \mathrm{f}$. Tese (Doutorado em Educação) - Universidade Metodista de Piracicaba, Piracicaba, SP, 2003.

SACRISTÁN, Gimeno; GÓMEZ, Pérez. Compreender e transformar o ensino. Porto Alegre: Artmed, 1998.

SANTOS, Boaventura de Sousa. Para ampliar o cânone democrático. In: SANTOS, Boaventura de Sousa (Org.). Democratizar a democracia: os caminhos da democracia participativa. Rio de Janeiro: Civilização Brasileira, 2002.

SANTOS, Boaventura de Sousa. Os processos da globalização. In: SANTOS, Boaventura de Sousa. (Org.). Globalização: fatalidade ou utopia. Porto: Afrontamento, 2001. 
SAVIANI, Demerval. Pedagogia histórico-crítica: primeiras aproximações, Campinas: Autores Associados, 2000.

SCHÖN, Donald. Educando o profissional reflexivo: um novo design para o ensino e a aprendizagem. Porto Alegre: Artmed, 2000.

SMYTH, John. Teachers' work and the politics of reflection. American Educational Research Journal, v. 29, n. 02, p. 267-300. 1992. Disponível em: 〈http://goo.gl/rP8tJt 〉. Acesso em: 30 jun. 2015. ISSN 0002-8312.

STENHOUSE, Lawrence. Investigatión y desarollo del curriculum. Madrid: Morata, 1994. SUOJANEN, U. Action research - a strategy for empowerment. In: K. Turkki (Org.). New approaches to the study of everyday life. Helsinki: Finland Publications 4, 1999.

THOUARD, Denis. Qu'est-ce qu'une herméneutique critique. Methodos, n. 02. 2002. Disponível em : 〈http://goo.gl/rMPoJX>. Acesso em: 21 mai. 2015.

WILSON, P. Empowering the self-directed team. Great Britain: Gower Publishing Limited, 1996. ZEICHNER, Kenneth. A formação reflexiva de professores - ideias e práticas. Lisboa: Educa, 1993.

ZEICHNER, Kenneth. Tradução de Cristina Antunes. Políticas de formação de professores nos Estados Unidos: como e por que elas afetam vários países no mundo. Belo Horizonte: Autêntica, 2013.

\section{Como citar este documento:}

FRANCO, Maria Amélia Santoro. Pesquisa-Ação Pedagógica: práticas de empoderamento e de participação. ETD Educação Temática Digital, Campinas, SP, v. 18, n. 2, abr./jun. 2016. ISSN 1676-2592. Disponível em: <http://periodicos.sbu.unicamp.br/ojs/index.php/etd/article/view/8637507>. Acesso em: 05 jul. 2016. doi:http://dx.doi.org/10.20396/etd.v18i2.8637507. 